\title{
Long-lived zircon growth in eclogite
}

\author{
M. HAND ${ }^{1}$, R. TAMBLYN ${ }^{1}$, D. ZIVAK
}

${ }^{1}$ Department of Earth Sciences, The University of Adelaide, Adelaide, Australia

In subduction environments, studies have documented apparently long-lived records of metamorphic zircon growth, that have important implications for the durations rocks can reside within subduction zones. Lawsonite-bearing eclogite occurs as a tectonic block in serpentinite mélange in the Southern New England Orogen in eastern Australia, and has a remarkable microstructural record of zircon growth. High resolution WDS X-ray and SEM mapping reveals the presence of thousands of 1-15 micron-sized zircons. These zircons: (1) define inclusion trails in garnets, (2) comprise a foliation defining matrix mineral, (3) form mantles around foliation defining minerals and (4) occur in late-stage veins with high-pressure minerals. In-situ derived concordant U$\mathrm{Pb}$ geochronology shows zircon growth occurred over a very long duration (c. 520-380 Ma), with the texturally young vein-hosted zircons giving ages at the young end of this spectrum. There is also an increase in zircon HREE concentrations with decreasing age. Together these indicate the age variation is consistent with zircon textural setting and changing paragenesis. The apparent long duration of zircon growth is also consistent with garnet, titanite and phengite geochronology from the eclogite.

We suggest the long record of zircon growth was facilitated by dissolution-precipitation in a fluid-rich high-pressure environment maintained by subduction. Speculatively, variations in fluid alkalinity and F-content buffered by the evolving mineralogy of the rock, promoted zircon dissolution or precipitation.

The apparent $100 \mathrm{Ma}+$ duration of zircon growth in this eclogite challenges conventional notions about how long rocks can stay entrained within subduction zones. Based on typical plate velocities, the duration high $\mathrm{P}$ zircon growth records $3000-5000 \mathrm{~km}$ or more of consumption of the palaeoPacific plate under east Gondwana indicating that thinsection scale samples of high-P rocks can place useful constraints on the minimum size of now extinct oceanic plates. 